\title{
VERNONIA CINEREA (NEICHITTI KEERAI) REGENERATES PROXIMAL TUBULES IN CISPLATIN- INDUCED RENAL DAMAGE IN MICE
}

\author{
ARUL AMUTHAN ${ }^{1,2}$, VASUDHA DEVI ${ }^{1 *}$, CHANDRASHEKARA SHASTRY SHREEDHARA ${ }^{3}$, VENKATA \\ RAO $^{4}$, KUNAL PURI ${ }^{5}$, SHINY JASPHIN ${ }^{6}$
}

\begin{abstract}
${ }^{1}$ Department of Pharmacology, Melaka Manipal Medical College, Manipal Academy of Higher Education, Manipal, Karnataka, India. ${ }^{2}$ Division of Siddha, Center for Integrative Medicine and Research, Manipal Academy of Higher Education, Manipal, Karnataka State, India. ${ }^{3}$ Department of Pharmacognosy, Manipal College of Pharmaceutical Sciences, Manipal Academy of Higher Education, Manipal, Karnataka, India. ${ }^{4}$ Department of Pharmaceutical Biotechnology, Manipal College of Pharmaceutical Sciences, Manipal Academy of Higher Education, Manipal, Karnataka, India. ${ }^{5}$ Department of Hematology, Medical College, Kolkata, India. ${ }^{6}$ National Post-Doctoral Fellowship (SERB), Melaka Manipal Medical College, Manipal Academy of Higher Education, Manipal, Karnataka State, India. Email: vasudha.devi@manipal.edu/v21devi@gmail.com
\end{abstract}

Received: 27 June 2018, Revised and Accepted: 29 September 2018

ABSTRACT

Objective: The aim of the study was to evaluate whether Vernonia cinerea (VC) regenerates the proximal renal tubular cells in cisplatin-induced necrosis in male Swiss albino mice.

Methods: The crude aqueous extract (CAE) of VC was fractionated from non-polar to polar using different solvents. Mice were injected a single dose of cisplatin ( $15 \mathrm{mg} / \mathrm{kg}$ ) on day 1 , which took 5 days to cause maximal renal damage. From day 6, CAE and all fractions were orally administered (200, 300 , and $400 \mathrm{mg} / \mathrm{kg}$ ) for 5 continuous days. On day 11, blood was collected to estimate urea and creatinine. Kidney was collected for histology and grading was done.

Results: Cisplatin induced proximal renal tubular damage (grade 5) in corticomedullary junction, characterized by necrosis, proximal tubular dilatation, inflammation and vasodilation. Aqueous fraction (AF) did not show any regeneration; whereas, $400 \mathrm{mg} / \mathrm{kg}$ dose of CAE and butanol fraction $(B F)$ showed a significant reduction $(\mathrm{p}<0.001)$ in proximal tubular damage (Grade 3 ) and 50-75\% regeneration of proximal tubular epithelial cells.

Conclusion: This is the first study to demonstrate the regenerative potential of Neichitti kashayam (CAE of VC) and its BF in cisplatin-induced proximal tubular damage in kidney. Further study is warranted to find out the dose regimen for complete regeneration, lead compounds, and molecular mechanism.

Keywords: Siddha, Ayurveda, Nephrotoxicity, Renal tubular damage, Tubular cells, Regeneration.

(C) 2019 The Authors. Published by Innovare Academic Sciences Pvt Ltd. This is an open access article under the CC BY license (http://creativecommons. org/licenses/by/4. 0/) DOI: http://dx.doi.org/10.22159/ajpcr.2019.v12i1.27464

\section{INTRODUCTION}

Cisplatin is an anticancer drug used in the treatment of solid organ cancers such as cervical, squamous cell carcinoma of head and neck, ovarian, testicular, bladder and lung cancers. It gets accumulated about 5 times the serum concentration in renal tubular epithelial cells; thus, the chances for nephrotoxicity are higher during cisplatin therapy. There are many reports on lack of recovery, progressive and permanent nephrotoxicity with successive treatment with cisplatin [1-3]. Risk factors for cisplatin nephrotoxicity include older age, smoking, dose, frequency, cumulative dose, pre-existing renal impairment, female gender, and hypoalbuminemia [2,3]. Cisplatin-induced inflammatory responses, damage to mitochondrial and nuclear DNA and reactive oxygen species lead to activation of both mitochondrial and non-mitochondrial apoptosis and necrosis in renal epithelial cells. Since the anticancer mechanism is responsible for the cisplatin-induced proximal tubular damage, strategies to treat should not compromise the anti-tumor activity of cisplatin [4]

No drugs have been approved by FDA to regenerate the renal tubular cells in cisplatin-induced renal damage. Many medicinal plants such as Catunaregam uliginosa, Mentha arvensis, Allium sativum, and Bassia malabarica have been studied for cisplatin-induced nephroprotective action [4-7]. Vernonia cinerea (VC) whole plant is used in traditional medicines to treat renal calculi, herpes, diarrhea, stomach pain, eczema, elephantiasis, cough, inflammations, skin diseases, fevers, ringworm, and conjunctivitis [8,9]. Different extracts of VC have been demonstrated for antioxidant, antipyretic, antidiarrhoea and anti-inflammatory properties. It downregulates pro-inflammatory cytokines [10-14].

Traditional Siddha Medicine literature suggests using VC decoction (polar crude aqueous extract [CAE]) to recover internal organ damage caused by metals and drugs [15]. The preliminary study with VC against sub-therapeutic dose of cisplatin $(6 \mathrm{mg} / \mathrm{kg})$ was evaluated using nonpolar extracts (petroleum ether, ethyl acetate, and alcoholic extract) and concluded that the plant improves renal function [16]. However, the therapeutic effect of $\mathrm{VC}$ on kidney was not been asserted through histopathology. None of the previous studies have assessed the regenerative potential of VC in damaged kidney caused by cisplatin. Therefore, this study was aimed to evaluate the therapeutic potential of VC in cisplatin-induced nephrotoxicity at dose extrapolated from the human dose and to assert this potential through histopathology.

\section{METHODS}

Plant collection, extraction, and fractionation

VC was collected from our institution campus, authenticated by a Taxonomy Expert from SDM Centre for Research in Ayurveda and Allied Sciences, Udupi, Karnataka, India, and the Voucher specimen was preserved (no. 604.15042404). The CAE of the whole plant was prepared by cold maceration method. Further fractionation was done using separating funnel by different solvents such as petroleum ether, chloroform, ethyl acetate, n-butanol, ethanol, and water. 
Laboratory animals

The study protocol was approved by Institutional Animal Ethics Committee, Kasturba Medical College, Manipal (Approval no: IAEC/ KMC/08/2014). Healthy adult male Swiss albino mice weighing between 27 and $37 \mathrm{~g}$ were used. Animals were housed in standard environmental condition (temperature $27 \pm 3^{\circ} \mathrm{C}$, photoperiod: Approximately $12 \mathrm{~h}$ natural light per day; relative humidity: $60 \pm 10 \%$ ) and fed with diets and water ad libitum. The mice were housed in polycarbonate cages, provided with standard mice food and filtered water. All mice were made to adapt to the housing conditions 1 week before the study.

\section{Study design and treatment}

Renal damage was induced by single intraperitoneal cisplatin injection (15 mg/kg, i.p) on day 1 [17]. Totally, we had 11 groups with six mice in each group as follows;

- Group 1: Normal mice

- Group 2: Cisplatin control (15 mg/kg, i.p)

- Group 3: Cisplatin (15 mg/kg, i.p) + CAE (200 mg/kg, oral)

- Group 4: Cisplatin (15 mg/kg, i.p) + CAE (300 mg/kg, oral)

- Group 5: Cisplatin (15 mg/kg, i.p) + CAE (400 mg/kg, oral)

- Group 6: Cisplatin (15 mg/kg, i.p) + butanol fraction (BF) (200 mg/kg, oral)

- Group 7: Cisplatin (15 mg/kg, i.p) + BF (300 mg/kg, oral)

- Group 8: Cisplatin (15 mg/kg, i.p) + BF (400 mg/kg, oral)

- Group 9: Cisplatin (15 mg/kg, i.p) + aqueous fraction (AF) (200 mg/kg, oral)

- Group 10: Cisplatin (15 mg/kg, i.p) + AF (300 mg/kg, oral)

- Group 11: Cisplatin (15 mg/kg, i.p) + AF (400 mg/kg, oral)

The extract and fractions were administered orally for 5 days from day 6 to day 10 . These three doses have been chosen based on acute toxicity study.

\section{Parameters assessed}

Body weight was assessed daily. On day 11, all the animals were anesthetized, and blood was collected. Blood urea, blood urea nitrogen (BUN), and creatinine were estimated from the plasma using the protocol provided by the Agappe Chemicals, India. The right kidney was collected from each animal for $\mathrm{H}$ and $\mathrm{E}$ histological assessment. The histology interpretation was done by the pathologist in the blinded slides. Histological scoring of renal tubular epithelial necrosis was done with mild modification from earlier scoring as follows; $0=$ normal, $1=$ up to $10 \%$ renal tubular epithelial (mild) necrosis, $2=10-25 \%$ renal tubular epithelial (moderate) necrosis, $3=26-50 \%$ renal tubular epithelial (moderate to severe) necrosis, $4=51-75 \%$ renal tubular epithelial (severe) necrosis, and $5=76-100 \%$ renal tubular epithelial (very severe/extensive) necrosis [18].

\section{Statistical analysis}

All the data were expressed in mean \pm SD. The data were analyzed using SPSS 11.0 version by one-way ANOVA followed by Dunnett's post hoc test. $\mathrm{p}<0.05$ was set as statistically significant.

\section{RESULTS}

Extraction and fractionations

The yield of CAE, BF, and AF of VC was $8.0,18.6$, and $81.4 \% \mathrm{w} / \mathrm{w}$, respectively. The qualitative phytochemical analysis showed the presence of carbohydrate, steroid, and saponin in CAE and BF; whereas the AF lacked saponins.

\section{Animal death}

Mice that developed diarrhea eventually died within the next 3 days. Most of the animals from $200 \mathrm{mg} / \mathrm{kg}$ to $300 \mathrm{mg} / \mathrm{kg}$ dose groups were not survived, which revealed that the lower doses (200 and $300 \mathrm{mg} / \mathrm{kg}$ ) were not able to protect the mice from cisplatin-induced toxicity (Table 1). Hence, normal control, cisplatin control, and $400 \mathrm{mg} / \mathrm{kg}$ doses of CAE, $\mathrm{BF}$, and $\mathrm{AF}$ were considered for further evaluation of the blood and histology parameters.

\section{Body weight}

There was a weight gain in normal mice, whereas cisplatin injection significantly $(\mathrm{p}<0.05)$ reduced the body weight. Treatment with VC from day 6-10 did not improve weight, but the weight remained stable from day 6 to day 11 (Fig. 1).

\section{Blood parameters}

The elevated levels of serum urea and BUN due to cisplatin-induced renal damage significantly $(\mathrm{p}<0.001)$ continued even on day 11 . The $\mathrm{CAE}$ did not reduce the elevated urea and BUN, whereas the BF and AF reduced the elevated urea and BUN, but this was not statistically significant. In addition, the creatinine level was normalized in cisplatin group spontaneously and in BF and AF treated groups after the $11^{\text {th }}$ day of cisplatin injection (Figs. 2 and 3). These parameters tell the general renal function, not the cisplatin specific toxicity, which is assessed by histology of kidney.

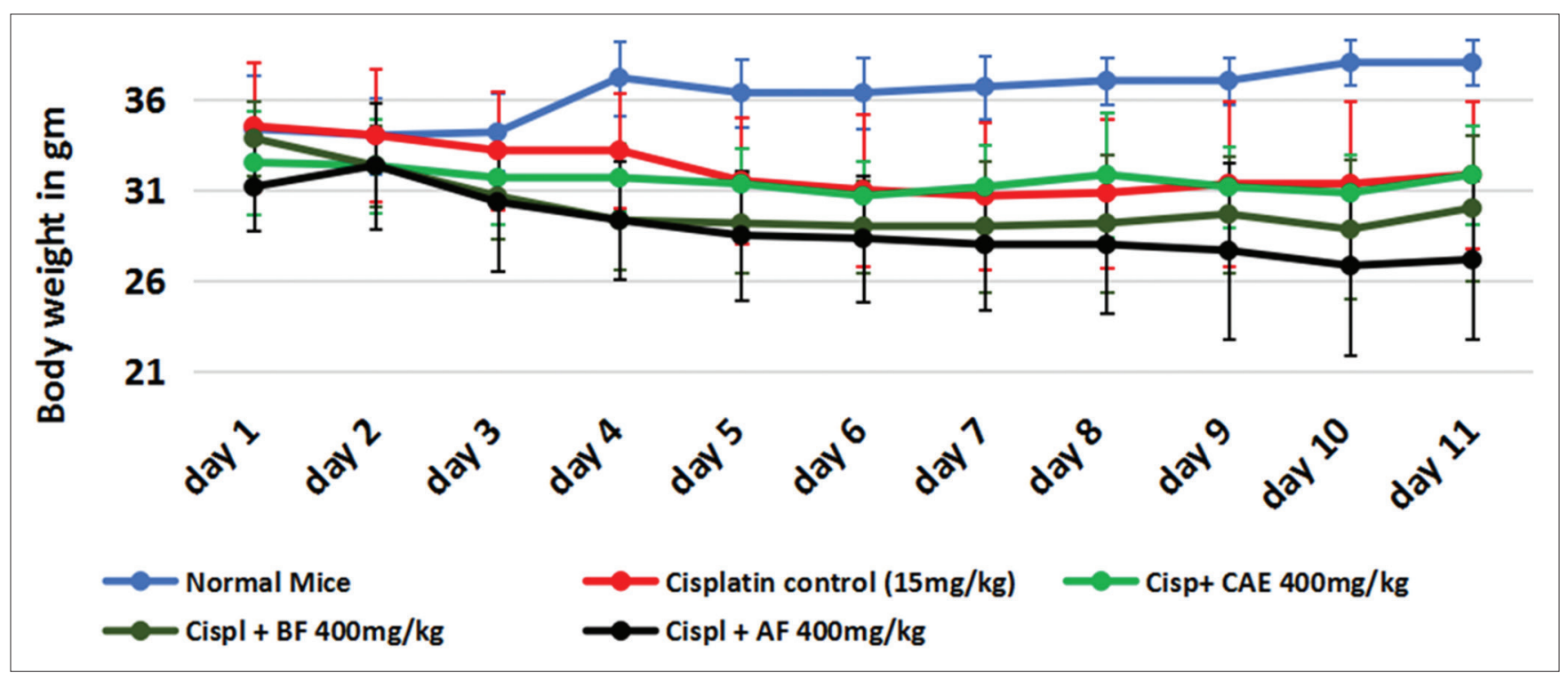

Fig. 1: The body weight changes due to cisplatin and Vernonia cinerea extract/fraction treatment. All values are expressed in mean \pm SD $\mathrm{n}=6$ in each group, cispl - cisplatin $15 \mathrm{mg} / \mathrm{kg}, \mathrm{CAE}$ - crude aqueous extract, $\mathrm{BF}$ - butanol fraction, AF - aqueous fraction 
Table 1: Number of animals died due to cisplatin toxicity

\begin{tabular}{lll}
\hline Group (n=6) & $\begin{array}{l}\text { Died } \\
\text { (out of 6) }\end{array}$ & $\begin{array}{l}\text { Survived } \\
\text { (out of 6) }\end{array}$ \\
\hline Control & 0 & 6 \\
Cisplatin control (15 mg/kg, i.p) & 2 & 4 \\
Cisplatin (15 mg/kg, i.p) + CAE 200 mg/kg & 5 & 1 \\
Cisplatin (15 mg/kg, i.p) + CAE 300 mg/kg & 5 & 1 \\
Cisplatin (15 mg/kg, i.p) + CAE 400 mg/kg & 0 & 6 \\
Cisplatin (15 mg/kg, i.p) + BF 200 mg/kg & 5 & 1 \\
Cisplatin (15 mg/kg, i.p) + BF 300 mg/kg & 5 & 1 \\
Cisplatin (15 mg/kg, i.p) + BF 400 mg/kg & 0 & 6 \\
Cisplatin (15 mg/kg, i.p) + AF 200 mg/kg & 6 & 0 \\
Cisplatin (15 mg/kg, i.p) + AF 300 mg/kg & 5 & 1 \\
Cisplatin (15 mg/kg, i.p) + AF 400 mg/kg & 0 & 6 \\
\hline
\end{tabular}

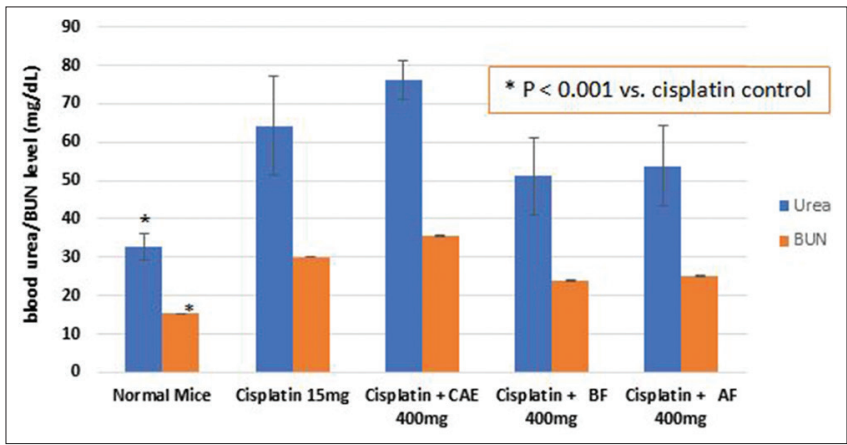

Fig. 2: Urea and blood urea nitrogen in mice with cisplatininduced nephrotoxicity and treated with Vernonia cinerea aqueous extract, butanol fraction, and water fraction. All values are expressed in mean $\pm S D, n=6$ in each group, cisplatin - cisplatin $15 \mathrm{mg} / \mathrm{kg}$, CAE - crude aqueous extract, BF - butanol fraction, AF - aqueous fraction

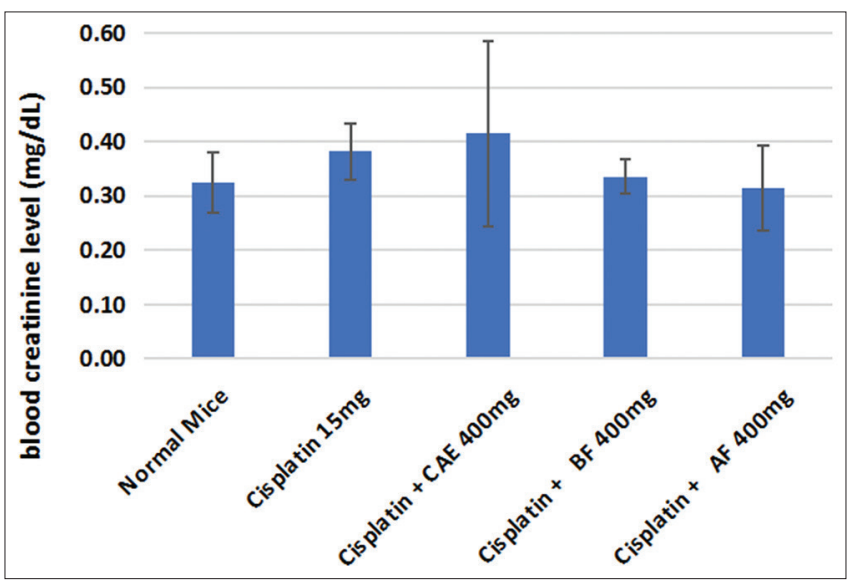

Fig. 3: Creatinine in mice with cisplatin-induced nephrotoxicity and treated with Vernonia cinerea aqueous extract, butanol fraction, and water fraction. All values are expressed in mean \pm $\mathrm{SD}, \mathrm{n}=6$ in each group, cisplatin - cisplatin $15 \mathrm{mg} / \mathrm{kg}$, CAE - crude aqueous extract, BF - butanol fraction, AF - aqueous fraction

\section{Histopathology of kidney}

The glomerulus and distal tubules were not disturbed by cisplatin. The nephron damage was not observed in the outer cortex or inner medullary region, but the maximum damage was observed in corticomedullary junction area. $75-85 \%$ of proximal tubular had damaged in corticomedullary junction in cisplatin-treated group which was characterized by necrosis, proximal tubules dilatation, inflammation, and vasodilation. Similar changes were observed in AF treated group; whereas, in CAE and BF treated groups, $25-50 \%$ of

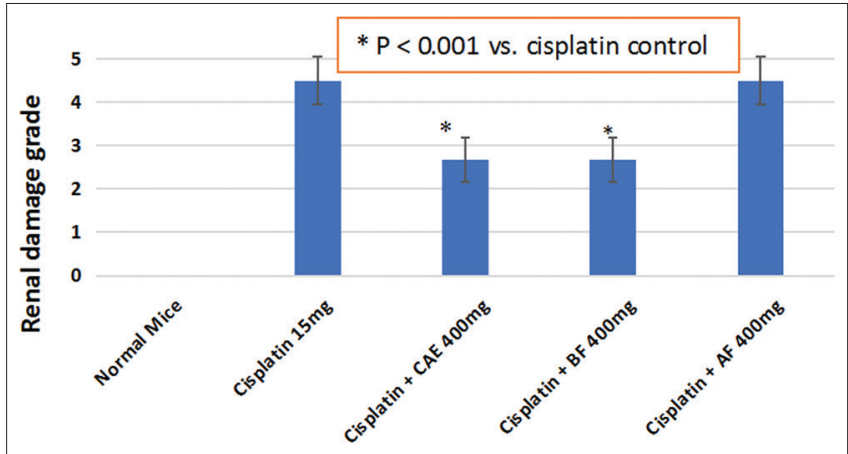

Fig. 4: Effect of Vernonia cinerea extract and fractions on cisplatininduced renal necrosis. All values are expressed in mean $\pm S D$, $\mathrm{n}=6$ in each group, cisplatin - cisplatin $15 \mathrm{mg} / \mathrm{kg}$, CAE - crude aqueous extract, BF - butanol fraction, AF - aqueous fraction

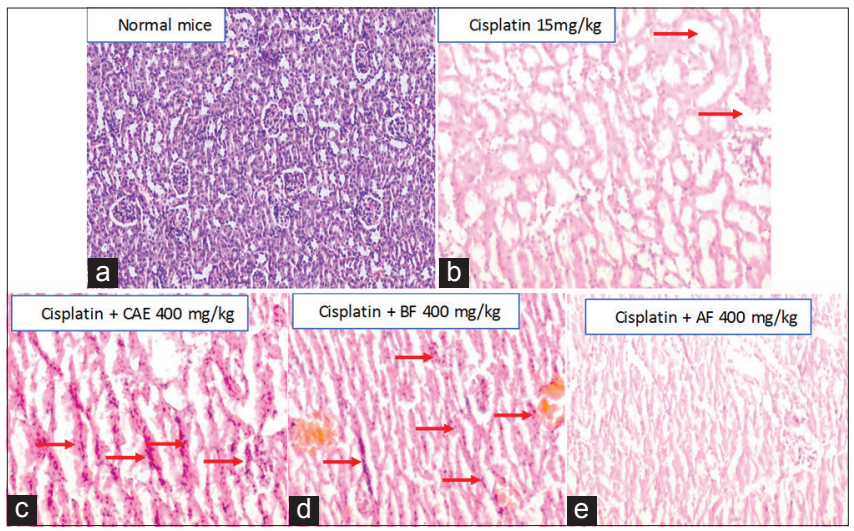

Fig. 5: Histology of kidney with cisplatin-induced nephrotoxicity and treated with Vernonia cinerea aqueous extract, butanol fraction, and water fractions $(\times 10)$. (a) Normal kidney shows normal glomerulus, proximal tubules, distal tubules, and vasculature, (b) cisplatin injection damaged $75-85 \%$ of proximal tubules in cortico-medullary junction characterized by necrosis, proximal tubular dilatation, inflammation, and vasodilation, (c and d) crude aqueous extract and BF treated groups with reduction in the proximal tubular damage and 50-75\% regeneration in proximal tubular cells, (e) aqueous fraction with no change in the renal tubular damage

proximal tubular had damaged. In addition, CAE and BF had induced regeneration in $50-75 \%$ of proximal tubular epithelial cells. The histological renal damage grade was significantly $(\mathrm{p}<0.001)$ lower in the crude aqueous extract as well as BF treated groups compared to cisplatin alone (Figs. 4 and 5).

\section{DISCUSSION}

Various Indian herbals such as Caesalpinia bonduc, Momordica dioica, and Morinda citrifolia have been reported for its renal protective effect against cisplatin $[19,20]$. VC is being used in Siddha Medicine to recover internal organ damage caused by metals and drugs. This property could be used to recover kidneys from cisplatin-induced toxicity in cancer patients. In our study, we used decoction (CAE) of VC and its two fractions to evaluate the property of recovering kidney from cisplatininduced toxicity in mice.

Nephrotoxicity was induced by injecting a single dose of cisplatin (15 mg/kg) intraperitoneally. Low doses (200 and $300 \mathrm{mg} / \mathrm{kg}$ ) of VC extract/fractions did not recover the cisplatin-induced toxicity; whereas $400 \mathrm{mg} / \mathrm{kg}$ treatment did. The herbal extracts/fractions did not significantly increase the body weight in mice with cisplatininduced weight reduction. 
The renal histology is an important tool to assess the renal recovery state. In this study, the histology revealed that cisplatin did not damage the glomerulus. Damage specifically to proximal tubules in the corticomedullary junction could be due to the 5 times higher accumulation of cisplatin [1]. Even after 11 days post-injection, the cisplatin-induced proximal renal tubular damage persisted as apoptosis, necrosis, loss of epithelial cells in proximal tubule, dilatation of proximal tubules, vasodilation, and inflammatory infiltration. The extent of tubular necrosis caused by cisplatin was graded as 5 (75-85\% tubular necrosis), which was significantly reduced to Grade 3 (25-50\%) by CAE (Neichitti kashayam) and BF, and both of them also showed additional regeneration (50-75\%) of proximal tubular epithelial cells. The recovery of renal tubules with tubular cells regeneration in cisplatin-induced renal damage by the herbal paves the way for drug discovery. In this study, there was no complete reversal from damage, which could be achieved probably by long-term treatment or higher doses or earlier intervention. No previous studies have evaluated the proximal renal cell regeneration activity of VC. This is the first study to show the regenerative ability of VC in renal tubules.

Antioxidant and anti-inflammatory actions of VC by reducing IL-6 level through an inhibition of BF-KB nuclear translocation might be the possible mechanisms behind the reduction in proximal tubular necrosis $[21,22]$.

The major phytoconstituents of VC include lupeol, lupeol acetate, luteolin-7O-glucoside, stigmasterol- $\beta$-D-glucopyranoside, $\beta$-amyrin, stigmasterol, and dotriacontanoic acid. Other minor phytochemicals are luteolin, $\alpha$-amyrin, lupeol palmitate, isoorientin, luteolin-7-0-glucuronide, diosmetin, chrysoeriol, $\beta$-amyrin acetate, $\alpha$-amyrin acetate, $\alpha$-amyrin palmitate, $\delta$-amyrin acetate, 26-methylheltacosanoic acid, stigmast-5,17(20)-dien$3 \beta$-ol, campersterol, $3 \beta$-acetoxyurs-13(18)-ene, 3 $\beta$-acetoxyurs-19-ene, 24 -hydroxy taraxer-14-ene, $\alpha$-spinasterol, $\beta$-sitosterol, and sitosterol [23]. The recovery of kidney with proximal tubular epithelial regeneration in cisplatin-induced renal damage could be due to these phytochemicals. However, further studies to be carried out to identify the lead compound.

\section{CONCLUSION}

N. kashayam (CAE of $\mathrm{VC}$ ) and its BF have shown significant recovery with cell regeneration in cisplatin-induced proximal tubular damage in kidney. This is the first study to give scientific support for traditional Siddha practice and demonstrate the regenerative potential of this plant. BF of $\mathrm{VC}$ is the potent candidate for drug discovery to recover kidney damage during cisplatin therapy among cancer patients. Further study is warranted to find the dose regimen for complete regeneration, lead compounds, and the molecular mechanism.

\section{AUTHORS' CONTRIBUTION}

Arul Amuthan and Vasudha Devi were involved in conceptualization of the original idea. All authors have involved in the designing the study protocol, collection of data, analysis, writing article, and revision of article. Arul Amuthan and Shreedhar have involved in the extraction of plant. Arul Amuthan and Venkata Rao have involved in animal experiment. Kunal Puri and Shiny Jasphin have involved in the histology slides preparation and interpretation.

\section{CONFLICTS OF INTEREST}

None.

\section{REFERENCES}

1. Yao X, Panichpisal K, Kurtzman N, Nugent K. Cisplatin nephrotoxicity: A review. Am J Med Sci 2007;334:115-24.
2. Santoso JT, Lucci JA, Coleman RL, Schafer I, Hannigan EV. Saline, mannitol, and furosemide hydration in acute cisplatin nephrotoxicity: A randomized trial. Cancer Chemother Pharmacol 2003;52:13-8.

3. Taguchi T, Nazneen A, Abid MR, Razzaque MS. Cisplatinassociated nephrotoxicity and pathological events. Contrib Nephrol 2005; 148:107-21.

4. Adikay S, Sravanthi U. Alleviation of cisplatin-induced nephrotoxicity in albino rats by roots of Catunaregam uliginosa. Asian J Pharm Clin Res 2016;9:147-51.

5. Singh RK, Gautam RK, Karchuli MS. Evaluation of nephroprotective activity of Mentha arvensis in cisplatin-induced nephrotoxicity. Asian J Pharm Clin Res 2014;7:188-91.

6. Anusuya1 N, Durgadevi P, Dhinek A, Mythily S. Nephroprotective effect of ethanolic extract of garlic (Allium sativum 1.) on cisplatin induced nephrotoxicity in male wistar rats. Asian J Pharm Clin Res 2013;6:97-100.

7. Sushma M, Prasad KV, Bai DJ, Vijay R, Rao VU. Prophylactic and curative effect of ethanolic extract of Bassia malabarica bark against cisplatin induced nephrotoxicity. Asian J Pharm Clin Res 2014;7:143-6.

8. Varier PS. Indian Medicinal Plants. Vol. 5. Chennai: Orietnal Longman Private Ltd.; 2004. p. 358-60

9. Kirtikar KR, Basu BD. Indian Medicinal Plants-II. New India, New Connaught Place, Dehradun: International Book Distributors; 1978. p. $13,232$.

10. Iwalewa EO, Iwalewa OJ, Adeboye JO. Analgesic, antipyretic, antiinflammatory effects of methanol, chloroform and ether extracts of Vernonia cinerea less leaf. J Ethnopharmacol 2003;86:229-34.

11. Gupta M, Mazumder UK, Manikandan L, Bhattacharya S, Haldar PK, Roy S, et al. Evaluation of antipyretic potential of Vernonia cinerea extract in rats. Phytother Res 2003;17:804-6.

12. Latha LY, Darah I, Jain K, Sasidharan S. Effects of Vernonia cinerea less methanol extract on growth and morphogenesis of Candida albicans. Eur Rev Med Pharmacol Sci 2011;15:543-9.

13. Ganesh P, Kumar KV, Kumar HS. Antidiarrhoeal activity of methanolic extract of Vernonia cinerea (L.) Less on female albino rats. Int Res J Pharm 2011;2:211-3

14. Kumar PP, Kuttan G. Vernonia cinerea L. Scavenges free radicals and regulates nitric oxide and proinflammatory cytokines profile in carrageenan induced paw edema model. Immunopharmacol Immunotoxicol 2009;31:94-102.

15. Pillai CK. Siddha Materia Medica-Vegetable Kingdom. Vol. 1. India: Rathna Nayakar and Sons; 2006. p. 472-3.

16. Sreedevi A, Bharathi K, Prasad KV. Effect of Vernonia cinerea aerial parts against cisplatin-induced nephrotoxicity in rats. Pharmacol Online 2011;2:548-55.

17. Ciarimboli G, Deuster D, KniefA, Sperling M, Holtkamp M, Edemier B, et al. Organic cation transporter 2 mediates cisplatin-induced oto-and nephrotoxicity and is a target for protective interventions. Am J Pathol 2010;176:1169-80

18. Lee S, Kim W, Moon SO, Sung MJ, Kim DH, Kang KP, et al. Rosiglitazone ameliorates cisplatin-induced renal injury in mice. Nephrol Dial Transplant 2006;21:2096-105

19. Ali M, Mruthunjaya K, Nandini C, Nabeel K, Manjula SN. Chemoprotective effect of noni (Morinda citrifolia L.) fruit juice against cisplatin-induced Nephrotoxicity. Int J Pharm Pharm Sci 2016;8:105-10

20. Talukdar A, Kalita RD, Gohain N, Saikia K, Kalita MC. Nephroprotective activity of the ethnomedicinal plants Caesalpinia bonduc and Momordica dioica from NE India against cisplatin induced chemotherapeutic toxicity. Int J Pharm Pharm Sci 2018;10:96-103.

21. Nishadh A, Gokilaveni C, Selvi A, Mahalakshmi R. Antioxidant activities of ethanolic extract of Vernonia cinerea in carbon tetrachloride induced hepatic damage in rats. Int J Curr Res 2013;5:1441-4.

22. Laosim T, Chuchawankul S, Tencomnao T. Immunomodulatory effect of hexane extract of Vernonia cinerea Less. Trunk on human peripheral blood mononuclear cells. J Chem Pharm Res 2011;3:188-95.

23. Haque A, Hassan M, Das A, Begam B, Ali Y, Moshed H. Phytochemical investigation of Vernonia cinerea (Family: Asteracae). J Appl Pharm Sci 2012;2:79-83. 